\title{
Direitos Humanos, Universidade e Políticas Públicas: um caminho para a educação
}

\section{libertadora}

\author{
Human Boards, University and Public Policy: a path to a liberating education \\ Juntas Humanitarias, Universidad y Políticas Públicas: un camino hacia una educación liberadora
}

Recebido:16/01/2021 | Revisado: 19/01/2021 | Aceito: 20/01/2021 | Publicado: 25/01/2021

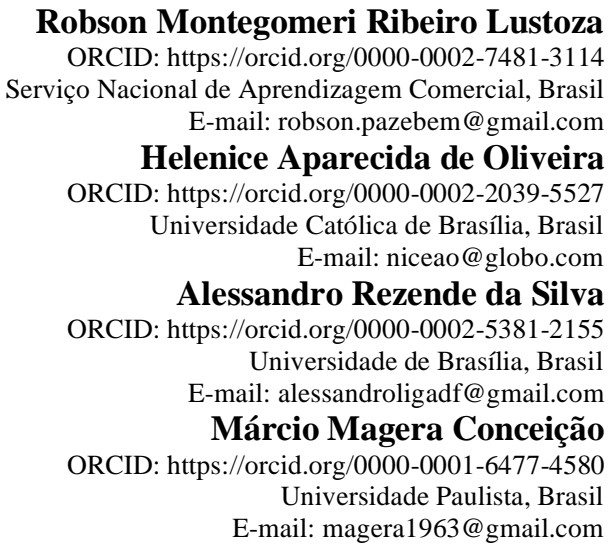

\begin{abstract}
Resumo
Este trabalho tem como objetivos analisar alguns conceitos sobre as políticas públicas de acesso à educação de acordo com os artigos propostos inicialmente na Declaração Universal dos Direitos Humanos e na atualidade, após os 70 anos de aprovação da DUDH. Diferenciar os conceitos de Educação para os Direitos Humanos à luz de estudos de alguns autores. Destaca-se, também, a Universidade como um local privilegiado de formação e informação para os estudantes e futuros profissionais havendo previsões claras nas políticas públicas para a Educação em Direitos Humanos no Ensino superior. E por fim, verificar como estão as ações programáticas para a educação em direitos humanos nas IES (Instituições de Ensino Superior) em cujo cenário é propício à discussão sobre essas políticas, refletidas e positivadas de acordo com o PNDH (Plano Nacional de Direitos Humanos), programa do Governo Federal criado a partir do art. 84, inciso IV, da Constituição, pelo Decreto ${ }^{\circ} 1904$ de 13 de maio de 1996, "contendo diagnóstico da situação desses direitos no país e medidas para a sua defesa e promoção; e de acordo com o PNEDH (Plano Nacional de Educação em Direitos Humanos), fruto do compromisso do Estado com a concretização dos direitos humanos e de uma construção histórica da sociedade civil organizada.
\end{abstract}

Palavras-chave: Direitos Humanos; Desafios; Educação; Políticas; Públicas; Universidade.

\begin{abstract}
This work aims to analyse some concepts about public access policies education according to the proposed articles initially in the declaration of human rights and nowadays, after 70 years of DDH approval. Differentiate the concepts of humans rights education between the humans rights education in the light of studies by some authors. The university is a privileged place of formation and information to the students and future professionals with clear predictions in public policies to the education in human rights in higher education. At least, check how the programmatic actions are doing to the education in human rights in the HEI (Higher Education Institutions), whose scenario is conducive to the discussion on these policies, reflected and made positive according to PNDH (Plano Nacional de Direitos Humanos - National Human Rights Plan ), federal government program created from the art. 84, item IV, from constitution, by decree nr. 1904 from may 13, 1996, containing diagnosis of the situation of these rights in the country and measure for its defense and promotion; and according to PNEDH (National Human Rights Education Plan - Plano Nacional de Educação em Direitos Humanos), the result of the state's commitment to the realization of human rights and a historic construction of organized civil society.
\end{abstract}

Keywords: Human rights; Challenge; Education; Policies; Publics; University.

\section{Resumen}

Este artículo tiene como objetivo analizar algunos conceptos sobre políticas públicas de acceso a la educación de acuerdo con los artículos propuestos inicialmente en la Declaración Universal de Derechos Humanos y hoy, luego de 70 años de aprobación por la DUDH. Diferenciar los conceptos de Educación para los Derechos Humanos a la luz de 
estudios de algunos autores. La Universidad también se destaca como un lugar privilegiado de formación e información para estudiantes y futuros profesionales, con claras predicciones en las políticas públicas de Educación en Derechos Humanos en la Educación Superior. Y finalmente, ver cómo son las acciones programáticas para la educación en derechos humanos en las IES (Instituciones de Educación Superior) en las que el escenario es propicio para la discusión de estas políticas, reflejado y confirmado de acuerdo con el PNDH (Plan Nacional de Derechos Humanos). , Programa del Gobierno Federal creado a partir del art. 84, inciso IV, de la Constitución, mediante Decreto No. 1904 de 13 de mayo de 1996, "que contiene un diagnóstico de la situación de estos derechos en el país y las medidas para su defensa y promoción; y de acuerdo con el PNEDH (Plan Nacional de Educación en Derechos Humanos), como resultado del compromiso del Estado con la realización de los derechos humanos y una construcción histórica de la sociedad civil organizada.

Palablas clave: Derechos humanos; Desafíos; Educación; Políticas; Público; Universidad.

\section{1- Introdução}

Nos seus mais de 70 anos, a Declaração dos Direitos Humanos tem se apresentado, ao longo do tempo, com grande importância para as nações, porém a sua concretização tem acontecido muito lentamente, diante da crueldade da luta pela sobrevivência frente a um sistema econômico que privilegia o acúmulo de capital em vez da qualidade de vida da coletividade.

Diante de um histórico de opressão e violação de direitos, pensar a Educação em Direitos Humanos no mundo, assim como no Brasil, não é algo que está ligado somente à questão de valores, mas, principalmente, ao posicionamento do sujeito enquanto agente de direito. Esse reposicionamento do sujeito se dá devido ao fato de a emancipação do cidadão ocorrer quando o sujeito de direitos reconhece seu papel na sociedade, seus direitos e deveres.

No Brasil, a relevância desse documento é incontestável, mas a aplicação dele ainda se configura como um grande desafio devido a fatores que dificultam a vivência de uma proposta da universalização dos Direitos Humanos num contexto de desigualdades. Observa-se que na história do Brasil houve uma colonização de caráter exploratório, em que os interesses dos colonizadores eram o de extrair as riquezas do país e torná-lo uma fonte de recurso material. Essa exploração gera reflexos no comportamento social dos brasileiros ainda hoje (Holanda, 2013).

É fato que na história, os Direitos Humanos têm sido tema de debate entre as comunidades internacionais. Contudo, pensar em Educação para os Direitos Humanos é algo relativamente recente na América Latina. A luta pelos Direitos Humanos representou um espaço de encontro entre educadores populares e militantes de Direitos Humanos que começa a se desenvolver com o final dos piores momentos da repressão política latina americana e que alcançou parcial sistematização na segunda metade da década de 1980 (Basombrio, 1992).

Ao longo dos anos na Educação brasileira, os Direitos Humanos têm se apresentado por meio das lutas contra os regimes autoritários sofridos no passado e hoje por meio da democracia com vistas às garantias dos direitos dos cidadãos (Candau, 2010).

E para que essa consciência aconteça é preciso uma Educação que promova essa realidade (Piovesan, 2010). Essa Educação tem que possibilitar o sujeito a exercer o ato político, a participação com direito de voz e vez nos processos sociais de forma consciente.

Por outro lado, as mudanças tecnológicas e ideológicas dos tempos atuais, como a globalização, o acesso rápido às informações permitiu que o conhecimento produzido chegue com mais celeridade às várias correntes do pensamento educacional no cenário mundial, ocasionando um alinhamento com as propostas do pensamento político internacional.

Dentre as tentativas de corroborar com a efetivação dessa proposta e na busca do melhor caminho para a Educação nacional, emergiu no Brasil, já na década de 1980, a preocupação com a formação em e para os Direitos Humanos do cidadão brasileiro (Basombrio, 1992).

Essa Educação tem que possibilitar o sujeito a exercer o ato político, a participação com direito de voz e vez nos processos sociais de forma consciente. 
Dessa forma, os Direitos Humanos constituem-se uma conduta ética inerente aos processos de formação cultural do homem. Eles, enquanto direitos, precedem a sua positivação, pois emergem da própria existência humana como condição inalienável e garantida. Compreender e promover esse universo são desafios conferidos à Educação para os Direitos Humanos, pois é através dela que se proporciona o conhecimento de tais direitos. A Universidade é um dos lócus de disseminação da informação e formação desse campo de atuação e nos seus currículos no sentido de formar cidadãos ativos, agentes de transformação social.

Ademais, a Educação em Direitos Humanos torna-se o instrumento que possibilita o conhecimento de tais direitos de modo que sejam reconhecidos não somente como direito, mas também como dever de promoção de todos para a harmonia social. Nesse contexto, emergem as políticas públicas nacionais, observando os acordos internacionais na promoção deste tipo de Educação para os diversos segmentos da sociedade.

Entre os segmentos, destaca-se neste trabalho, a Universidade como um local privilegiado de formação e informação para os estudantes e futuros profissionais, havendo previsões claras nas políticas públicas para a Educação em Direitos Humanos no Ensino superior. Também destaca-se a juventude pela sua participação na vida social em busca de mudanças nos desafios surgidos em sua realidade.

\section{O Marco Histórico da Declaração dos Direitos Humanos e sua Importância}

A Declaração Universal dos Direitos Humanos completou 70 anos. Foi aprovada pela recém criada ONU Organização das Nações Unidas - em Paris - em 10 de dezembro de 1948. Contém 30 artigos cuja proposta é de ser uma norma comum a todos os países e povos para servir como base para o progresso e paz social. A DUDH é considerada o documento mais traduzido do mundo - para mais de 500 idiomas - e inspirou as constituições de vários Estados e democracias recentes.

$\mathrm{O}$ texto condena a escravidão e a tortura, defende o asilo para indivíduos perseguidos e o direito à educação gratuita, à liberdade de reunião e à propriedade privada e proclama que "todos os seres humanos nascem livres e iguais em dignidade e em direitos", "sem distinção alguma, nomeadamente de raça, de cor, de sexo, de língua, de religião, de opinião política ou outra, de origem nacional ou social, de fortuna, de nascimento ou de qualquer outra situação".

A Declaração Universal dos Direitos Humanos (DUDH) se apresenta como um dos principais documentos de referência para o pensamento em Direitos Humanos no mundo, pois há muito tempo as diversas nações pensavam em direitos coletivos, justiça social, igualdade, democracia, direito nas diversas esferas. Contudo, a interpretação desses conceitos era feita por cada nação que considerava a sua própria realidade e especificidades (Comparato, 2013).

Assim, o surgimento da DUDH emerge da necessidade de uma convergência nesse entendimento em busca de uma linguagem que seja comum a toda e qualquer pessoa.

No que concerne à educação, a Declaração Universal dos Direitos Humanos no artigo XXVI afirma:

1. Todo ser humano tem direito à instrução. A instrução será gratuita, pelo menos nos graus elementares e fundamentais. A instrução elementar será obrigatória. A instrução técnico-profissional será acessível a todos, bem como a instrução superior, está baseada no mérito.

2. A instrução será orientada no sentido do pleno desenvolvimento da personalidade humana e do fortalecimento do respeito pelos direitos do ser humano e pelas liberdades fundamentais. A instrução promoverá a compreensão, a tolerância e a amizade entre todas as nações e grupos raciais ou religiosos e coadjuvará as atividades das Nações Unidas em prol da manutenção da paz.

3. Os pais têm prioridade de direito na escolha do gênero de instrução que será ministrada a seus filhos. (Organização das Nações Unidas, 1948) 
Em seus mais de 70 anos de existência, a Declaração Universal dos Direitos Humanos, proclamada pelas Nações Unidas em 1948, cumpriu um importante papel na história da humanidade. Utilizando parte de análise feita por Alves (2005), destaca-se que a DUDH estabeleceu regras mundiais a serem seguidas, deu esperanças a todos os oprimidos de que seus direitos seriam respeitados equitativamente, forneceu linguagem autorizada ao sentido de suas reivindicações, proporcionou base legislativa às lutas políticas pela liberdade e igualdade, inspirou a maioria das constituições nacionais na positivação dos direitos ligados à cidadania, estabeleceu parâmetros para aferição da legitimidade de governos, estimulou ações solidárias e lançou bases, não só para um sistema legislativo internacional, mas para uma verdadeira comunidade internacional.

No que diz respeito ao artigo XXVI citado anteriormente, garantiu o direito de instrução por mérito a todos. Um exemplo próximo é a Constituição Federal (C.F.) de 1988, na qual o Brasil manifesta uma preocupação evidente ao instituir direitos e garantias fundamentais à população.

Ademais, a DUDH estimulou a adoção de inúmeros outros instrumentos internacionais, os quais foram adotados por países das mais diversas culturas e sistemas sociopolíticos ao redor do mundo. Destaca-se, nesse sentido, a Conferência Mundial dos Direitos Humanos, ocorrida em Viena, em 1993, a qual reuniu todos os países de um mundo praticamente sem colônias. Essa aderência ao sistema global ou ousado de Direitos Humanos ratifica a legitimação da Declaração Universal dos Direitos Humanos.

Aliado a essas ideias, o Programa Mundial para Educação em Direitos Humanos (PMEDH) entende que a educação em Direitos Humanos é um processo ao longo da vida que constrói conhecimentos e habilidades, assim como atitudes e comportamentos para promover e apoiar os Direitos Humanos como afirma abaixo:

O Programa Mundial de Educação em Direitos Humanos (ONU, 2005), ao propor a construção de uma cultura universal de direitos humanos por meio do conhecimento, de habilidades e atitudes, aponta para as instituições de ensino superior a nobre tarefa de formação de cidadãos(ãs) hábeis para participar de uma sociedade livre, democrática e tolerante com as diferenças étnico-racial, religiosa, cultural, territorial, físico-individual, geracional, de gênero, de orientação sexual, de opção política, de nacionalidade, dentre outras (Brasil, 2007, p.38).

Confluindo com essa ideia, Freire (2001) afirma que:

A educação para os direitos humanos, na perspectiva da justiça, é exatamente aquela educação que desperta os dominados para a necessidade da briga, da organização, da mobilização crítica, justa, democrática, séria, rigorosa, disciplinada, sem manipulações, com vistas à reinvenção do mundo, à reinvenção do poder. [...] essa educação tem que ver com uma compreensão diferente do desenvolvimento, que implica uma participação, cada vez maior, crescente, crítica, afetiva, dos grupos populares (Freire, 2001, p. 99).

Compreender os Direitos Humanos e aplicá-los na vida é uma das formas de emancipação social. Contudo, considerando que não há neutralidade na educação e quando se faz a opção por uma educação voltada para os Direitos Humanos, Gorczevski (2009) ressalta a importância do cuidado na abordagem deste modelo para que o sujeito de direitos não se torne sujeito de discurso de direitos (Chauí \& Santos, 2013). Desta forma, deve-se ter claro a qual finalidade a educação está atendendo.

Dessa forma, é na conjuntura das intensas e rápidas transformações sociais que tem ganhado espaço a luta de vários grupos sociais por uma educação que atenda e garanta os Direitos Humanos. Sabemos que esses direitos não são concessões do Estado para o cidadão, mas, sobretudo, fruto de intensas lutas. Na prática, eles não são dados, mas conquistados. No processo de conquista pelos Direitos Humanos, as leis constituem uma referência muito importante, pois uma verdadeira democracia somente se desenvolve no momento em que os Direitos Humanos sejam reconhecidos por uma Constituição (BOBBIO, 1987). 
Além disso, cabe ressaltar que mais importante que a lei é a necessidade de criar uma cultura em e para os Direitos Humanos, pois enquanto a lei consiste em um elemento extrínseco ao sujeito, a cultura é algo intrínseco e faz o sujeito agir de dentro de si, motivado por razões que ele conhece e adere.

As constituições são as diretrizes que conduzem os caminhos de diversos países. Nessa óptica, "as constituições democráticas têm por base o reconhecimento e a proteção dos Direitos Humanos, sendo a concretização dos direitos fundamentais o fundamento do Estado Democrático de Direito, e condição de sua manutenção" (KONRAD; GORCZEVSKI, 2013, p. 24).

No Brasil, no que se refere aos Direitos Humanos na Constituição Federal de 1988 (CF), destacamos a ampliação dos direitos e garantias fundamentais. No preâmbulo da CF está previsto um Estado democrático de direito no país, com vistas ao exercício dos direitos sociais e individuais, à liberdade, à segurança, ao bem-estar, ao desenvolvimento, à igualdade e à justiça, como valores supremos de uma sociedade fraterna, pluralista e sem preconceitos (Brasil, 2014).

Quanto à questão da Educação na Constituição Brasileira, dá-se destaque ao artigo 203 quando indica que:

A educação, direito de todos e dever do Estado e da família, será promovida e incentivada com a colaboração da sociedade, visando ao pleno desenvolvimento da pessoa, seu preparo para o exercício da cidadania e sua qualificação para o trabalho (Brasil, 2014).

Observa-se pelo artigo que a educação no Brasil deve ter contribuição não só do Estado, mas também da família e da sociedade. Embora tenha o aval legal do Estado desse direito, as ações de viabilização da educação devem ser realizadas por todos. As leis não transformam a realidade rapidamente, elas são fontes de esperança para os indivíduos mudarem determinadas realidades, pois caso não existissem e não fossem colocadas como uma responsabilidade para o poder público cumprir, os cidadãos não teriam garantidos os seus direitos nos diversos setores da vida social (Freire, 1997).

No caso das leis educacionais não é diferente, pois elas também traduzem os anseios e sonhos dos atores que as concebem e aplicam. Assim, é importante lembrar que sonhar, como nos ensinou o grande educador Paulo Freire, é um elemento que faz parte da própria natureza humana. Na prática, a esperança que as leis nos trazem é importante para essa dimensão do ser humano. As leis e normas promulgadas pelo Estado tendem a garantir a todos os cidadãos os seus direitos, assim como condições para exercerem seus deveres, através de políticas publicas adequadas.

Assim, pode-se concluir que as leis positivadas consistem em um arcabouço teórico, que diante do pensamento jus positivista vivido neste tempo, representa a possibilidade da aplicação do que se foi pensado nas políticas públicas para os Direitos Humanos no Brasil e no mundo.

\section{Direitos Humanos: Breves Considerações}

Enquanto direitos, eles precedem a sua positivação, pois emergem da própria existência humana como condição inalienável e garantida. Dessa forma, a Educação conduz à promoção dos Direitos Humanos na possibilidade da compreensão entre as nações para a paz social, no resguardo dos direitos e na dignidade humana. Compreender e promover esse universo são desafios impostos à Educação.

Os Direitos Humanos surgem a partir dos direitos naturais inerentes a todos os homens. Eles se ampliam a partir dos processos culturais desenvolvidos socialmente e são positivados na busca de uma compreensão coletiva e no entendimento de uma sociedade complexa que necessita de novos rumos em sua convivência para o bem comum.

Os Direitos Humanos se efetivam nas relações humanas e diante desse fato, algumas questões nos ajudam nessas reflexões: $\mathrm{O}$ homem se faz humano nos processos culturais que desenvolve ou já possui essa condição inata a partir de sua existência? A igualdade enquanto ser humano é apreendida nos bancos escolares ou já se encontra no interior da própria 
condição de se nascer humano? Como os estudantes do ensino superior percebem o processo de reconhecimento dos Direitos Humanos em sua formação?

O respeito ao outro deve pautar-se na isonomia que é um elemento que deve ser entendido como algo próprio de cada pessoa. A percepção do outro como igual em direitos e deveres é uma compreensão inerente a todos os sujeitos, ou deveria ser, partindo do pressuposto de que possuem constituições semelhantes tanto físicas quanto biológicas. De acordo com Comparato (2013), uma sociedade que se quer humanizada requer sujeitos conscientes de uma identidade com seus semelhantes.

Os Direitos Humanos tratam desses preceitos não no sentido de uniformizar comportamentos e relações, mas na busca de uma convergência do respeito e diálogo no que se refere às diferenças e aos interesses que os grupos sociais buscam defender. Essas relações dialógicas favorecem um crescimento coletivo em meio à diversidade, proporcionando um ambiente favorável à vida. Dias (2010), amplia essa discussão afirmando que as novas gerações necessitam da Educação em e para os Direitos Humanos como uma medida eficaz de enfrentamento às formas de intolerância, de desrespeito, de discriminação contra as pessoas e de violação a condição de dignidade humana.

A Declaração de Viena, que representa um marco na conquista pelo reconhecimento da Educação em Direitos Humanos, concebe que os Direitos Humanos possuem uma natureza universal, pois abarca direitos distintos tais como o direito à Educação, às liberdades, ao desenvolvimento dentre outros (Brasil, 2013).

Pode-se considerar também que os Direitos Humanos possuem uma vocação coletiva, na compreensão de estar voltado para todos os sujeitos e, desta forma, o que é comum resguarda aquilo que é próprio do singular.

Na compreensão de Ruiz (2010, p. 193), "os Direitos Humanos entram em cena na modernidade como direitos do sujeito, identificados como os direitos do eu. A relação entre os direitos e o sujeito é tão estreita que no horizonte conceitual da modernidade chegam a se confundir como similares". Esta ampliação dos direitos individuais atribui aos Diretos Humanos o privilégio de proteção dos sujeitos no que se refere às transformações políticas e socioeconômicas que fazem parte da evolução dos Estados (Brasil, 2013).

Os Direitos Humanos podem ser concebidos de diferentes formas. A abordagem do racionalismo jus naturalista defende a ideia de que os Direitos Humanos independem da vontade humana e estão acima da positivação das leis. Procedem da existência de leis naturais e têm como pressuposto os valores do ser humano em busca de um ideal de justiça.

Essa ideia é tão forte e arraigada na concepção moderna que ela os tem como direitos naturais inalienáveis (RUIZ, 2010). Essa abordagem possui ramificações de acordo com as várias ideologias vigentes no curso da história. O posicionamento moderno, por exemplo, considera uma perspectiva ampliada na atualidade que se refere ao individualismo, nos seus aspectos de seus direitos, liberdades e propriedade. Segundo Bobbio (1998) o jus naturalismo moderno, pensado por Locke e Kant, é enfatizado na defesa dos direitos naturais, inatos e racionais do sujeito.

$\mathrm{Na}$ tentativa de conceituar os Direitos Humanos, percebe-se que entre os pensadores não há um consenso quanto ao conceito da temática em questão. Alguns autores defendem a ideia de que sistematizar tal conceito, sempre seria insuficiente devido à amplitude do tema. Outros se posicionam diretamente expondo suas percepções, mesmo considerado os possíveis riscos de generalizações.

Para Bobbio (2004), não existe um fundamento absoluto acerca dos Direitos Humanos. Ele justifica que a expressão Direitos Humanos constitui-se em uma expressão muito vaga. Também considera que os Direitos Humanos constituem-se em uma classe de direito variável historicamente. Outro aspecto importante, observado pelo autor é que os Direitos Humanos são muito heterogêneos, não possuem um fundamento absoluto e constituem-se em contínuas crises (Bobbio, 2004, p. 17-19). Já para Dallari (2002, p. 23), os Direitos Humanos são concebidos de forma objetiva, relacionando-os aos direitos fundamentais.

Assim, para que as pessoas consigam se desenvolver e participar ativamente da vida social é por meio dos Direitos Humanos que isso ocorrerá. Mesmo não havendo um consenso acerca do conceito dos Direitos Humanos entre os estudiosos 
do assunto, o importante nessa discussão é que não há dúvidas quanto ao significado desses direitos no reconhecimento da pessoa humana.

O desafio que se impõe é a aplicação de tais direitos e fazer com que eles sejam respeitados e conhecidos. Nesse sentido, a Educação em e para os Direitos Humanos torna-se imprescindível na construção de uma cultura para os Direitos Humanos, reconhecida e vivida universalmente.

\section{Educação e Direitos Humanos}

A Educação é um processo cultural, conhecimento do homem acerca de sua realidade que se caracteriza por ser significante, criando uma identidade, e, significado, que dá sentido à existência e às inter-relações que se constroem nos processos sociais. Ela acontece em seus processos cognitivos e não cognitivos permitindo ao sujeito elaborar seus conceitos e pré-conceitos sobre a realidade.

Desde as antigas civilizações, o reconhecimento da importância da Educação tem destaque nas primeiras sociedades politicamente organizadas. As diversas nações já pensavam em direitos coletivos, justiça social, igualdade, democracia, direitos nas mais diversas esferas, isto se justificava devido às várias violações à dignidade humana realizadas no passado (Gorczevski, 2009).

O convívio em sociedade passa pela capacidade do homem de se fazer humano, de estar inseridos nos processos sociais e desenvolver suas habilidades, competências, atitudes e comportamentos na direção de uma vivência harmônica na esfera pessoal e coletiva. Nesse sentido, a educação é o instrumento que possibilita aos sujeitos se tornarem humanos (Dewey, 1979).

O indivíduo em seu processo educacional relaciona-se com diversos grupos sociais e instituições, e para que essas relações sejam possíveis, ele vivencia convenções sociais conhecidas como direitos e deveres. Nesse entendimento, os Direitos Humanos integram o conjunto dessas convenções sociais e trazem direcionamentos para esse processo de humanização. "Educar em Direitos Humanos é promover o conhecimento dos Direitos Humanos de modo que sejam percebidos não só como direito, mas também como dever de promoção de todos para a garantia da paz social no mundo" (Konrad \& Gorczevski, 2013 p. 19).

Nesse sentido, Gorczevski e Martín (2015) diferenciam Educação para os Direitos Humanos e Educação em Direitos Humanos. Na compreensão dos autores, a expressão Educação para os Direitos Humanos é entendida como a transmissão de conhecimentos sobre esses direitos por meio de seus documentos. Este fundamento tem como objetivo possibilitar o conhecimento e a vivência dos direitos pelo sujeito assim como reconhecer e respeitar os direitos das outras pessoas. Seu conteúdo expressa o sentido que os Direitos Humanos devem ter para os sujeitos que é de mobilizar o ser para as práticas de reconhecimento e promoção da vida.

Já o conceito de Educação em Direitos Humanos, como forma de aplicação de tais direitos no universo educacional, é estabelecido na relação da Educação em Direitos Humanos com os processos pedagógicos, com o método e as técnicas de transmissão deste conhecimento.

Outro aspecto igualmente importante no que se refere à Educação como o campo de aprendizagem e vivência dos Direitos Humanos refere-se à percepção do caráter político que a Educação em Direitos Humanos possui. Ela não está restrita ao ato de se educar somente em valores, mas também na capacidade de formar o cidadão numa perspectiva crítica da realidade que o cerca. A Educação constitui-se como um lócus natural de aplicação, consolidação e expansão dos direitos humanos; como um direito-chave (Estêvão, 2011). 
A Declaração Universal dos Direitos Humanos destaca essa realidade em seu artigo XXVI, quando assinala que toda a pessoa tem direito à educação, sendo que esta deve visar à plena expansão da personalidade humana e ao reforço dos Direitos Humanos e das liberdades fundamentais.

Nessa perspectiva, o Programa Mundial para Educação em Direitos Humanos (PMEDH) entende que a educação em Direitos Humanos é um processo permanente ao longo da vida escolar dos estudantes, capaz de construir conhecimentos, orientar atitudes e comportamentos para promover e apoiar os Direitos Humanos.

Compreender os Direitos Humanos e aplicá-los na vida é uma das formas de emancipação social. Contudo, considerando que não há neutralidade na educação, e quando se faz a opção por uma educação voltada para os Direitos Humanos, Gorczevski (2009) ressalta a importância do cuidado na abordagem dessa temática. Deve-se, portanto, ter claro a qual finalidade a educação está atendendo para que o sujeito de direitos não se torne sujeito de discurso de direitos (Chauí \& Santos, 2013).

É na conjuntura das intensas e rápidas transformações sociais que tem ganhado espaço a luta de vários grupos sociais por uma educação que atenda e garanta os Direitos Humanos. É sabido que esses direitos não são concessões do Estado para o cidadão, mas, sobretudo, fruto de intensas lutas; na prática, eles não são dados, mas conquistados. No processo de conquista pelos Direitos Humanos, as leis constituem uma referência muito importante, pois uma verdadeira democracia somente se desenvolve onde os Direitos Humanos sejam reconhecidos por uma Constituição (Bobbio, 1987). Cabe ressaltar que mais importante que a lei é a necessidade de criar uma cultura em e para os Direitos Humanos, pois enquanto a lei consiste em um elemento extrínseco ao sujeito, a cultura é algo intrínseco e faz o sujeito agir de dentro de si, motivado por razões que ele conhece e adere.

As leis não transformam a realidade rapidamente, elas são fontes de esperança para os indivíduos mudarem determinadas realidades, pois, caso não existissem e não fossem colocadas como uma responsabilidade para o poder público cumprir os cidadãos não teria garantidos os seus direitos, nos diversos setores da vida social (Freire, 1997).

Assim, as diretrizes e objetivos apresentados nos Programas Mundial e Nacional de Direitos Humanos, que constituem as políticas públicas em âmbito internacional e nacional, a partir do eixo orientador que trata da Educação e cultura em Direitos Humanos estão norteando e compondo o Plano Nacional de Educação em Direitos Humanos (PNEDH). Este documento aponta para um compromisso entre o Estado, por meio de seus membros, em especial o Poder Executivo em suas esferas, e os organismos internacionais, instituições de Ensino Superior e a sociedade civil organizada, na implementação de políticas públicas por uma cultura educacional em e para os Direitos Humanos.

\section{Políticas Públicas para a Formação em e para Direitos Humanos}

Os esforços das militâncias pelos Direitos Humanos e do compromisso do Estado na realização das políticas públicas internacionais e nacionais em Direitos Humanos resultaram no Plano Nacional de Educação em Direitos Humanos (PNEDH). O plano aprofunda questões presentes em programas nacionais anteriores e também incorpora aspectos dos principais documentos internacionais de Direitos Humanos, dos quais o Brasil é signatário, acrescentando questões antigas e contemporâneas de nossa sociedade visando uma cultura de paz. A atual versão do PNEDH foi elaborada em 2006 e o documento oficial foi lançado em 2007 (Brasil, 2007).

Entende-se que a proposta intenciona atender aos anseios de uma educação laica e democrática em consonância com as políticas preconizadas no país. Também, visa a construção de uma cultura em Direitos Humanos que, segundo o documento, será possível na totalidade da implantação do referido plano, considerando o tempo necessário para que este processo possa vir a ser apreendido e vivenciado pelo cidadão brasileiro. 
Quanto aos objetivos do PNEDH destacaram-se no trabalho realizado os que estão voltados para o Ensino Superior. O PNEDH prevê que as instituições de ensino superior formem cidadãos capazes de atuar autonomamente numa sociedade livre, democrática e tolerante com as diferenças (Brasil, 2007).

Os objetivos propostos no plano almejam contribuir para que os compromissos internacionais e nacionais com a Educação em Direitos Humanos se efetivem, estimulando assim, a cooperação nacional e internacional na implementação dessas ações. O PNEDH reafirma a questão do fortalecimento daquilo que já se prevê na própria Constituição e, também, em outros documentos como a Lei de Diretrizes e Bases da Educação brasileira. Observa-se que muitas das leis brasileiras, que já estão em vigor, não são aplicadas, ferindo princípios básicos de Direitos Humanos.

No que concerne à Educação Superior, o PNEDH possui oito itens que contemplam os princípios norteadores da Educação para os Direitos Humanos, quais sejam: as universidades; as ações universitárias; da Educação em direitos humanos; a Educação em Direitos Humanos como princípio ético-político; os Direitos Humanos como tema transversal e transdisciplinar; a indissociabilidade entre ensino, pesquisa e extensão; a construção de uma cultura em Direitos Humanos; e a participação das IES. Tais princípios compõem um conjunto de orientações e regras que direcionam as ações que serão executadas na implantação do PNEDH, desta forma, torna-se importante a ampliação das questões que os envolve.

\section{Políticas Públicas Nacionais para a Formação em e para Direitos Humanos}

O Brasil como Estado-membro das Nações Unidas, observando os tratados internacionais mais recentes, seja do sistema das Organizações das Nações Unidas (ONU), seja das Organizações dos Estados Americanos (OEA), com vista à promoção dos Direitos Humanos e alinhando-se com a proposta do PMEDH, realizou em 2008 a $11^{\text {a }}$ Conferência Nacional de Direitos Humanos, procurando sistematizar o que fora produzido desde o ano de 2002. Neste evento, foi proposto um grande debate nacional sobre quais deveriam ser as prioridades que o Estado Brasileiro deveria assumir para o curso dos próximos anos. Como produto das reflexões e discussões, nasceu o Programa Nacional de Direitos Humanos III que foi publicado pelo Decreto Presidencial n ${ }^{\circ} 7.037 / 2009$.

O programa objetiva continuar a integração e o aprimoramento dos mecanismos de pesquisa existentes e criar novos meios de construção e acompanhamento das políticas públicas acerca dos Direitos Humanos no Brasil. Está estruturado em seis eixos orientadores: interação democrática entre Estado e Sociedade civil; desenvolvimento e Direitos Humanos; universalização dos direitos em um contexto de desigualdades; segurança pública - acesso à justiça e combate à violência; educação e cultura em Direitos Humanos e direito à memória e à verdade.

Quanto às formas de aplicação do PNDH III foram previstos planos de ações construídos a cada dois anos, sendo fixados os recursos orçamentários, as medidas concretas e os órgãos responsáveis pela execução. (Brasil, 2010).

O referido Programa, em sua constituição, teve como principal desafio político e metodológico a construção de um programa que considerasse a indivisibilidade e interdependência dos Direitos Humanos em todas as suas dimensões: direitos civis, políticos, econômicos, sociais, reprodutivos e ambientais (Ciconello, Pivato \& Frigo, 2009).

O PNDH III foi precedido pelo PNDH II, lançado em 2002, enfocou e incorporou os direitos econômicos sociais, culturais e ambientais, e, pelo PNDH I (1996) que evidenciou e enfocou os direitos civis e políticos. O PNDH I, publicado pelo Decreto presidencial No 1904 em 1996, foi instituído pelo Ministério da Justiça. Nesse mesmo período foi criada a Secretaria Nacional dos Direitos Humanos, órgão que ficou responsável pela coordenação, gerenciamento e acompanhamento da execução do programa (Brasil, 2010).

Entre os Direitos Humanos civis e políticos evidenciados no PNDH I, foram apresentadas 228 propostas de ações governamentais direcionadas a integridade física, liberdade e o espaço de cidadania de populações vulneráveis. Os pontos a serem melhorados no PNDH I e revistos no PNDH II, relacionam-se à incompatibilidade das propostas de ações 35 previstas 
no programa aos instrumentos de planejamento e orçamento. As propostas eram colocadas de forma genéricas, pouco afirmativas, culminando em processos de debates e construção do PNDH-II. O PNDH I inspirou o PNDH II, pois houve 519 propostas de ações sugeridas.

O PNDH II, publicado pelo Decreto Presidencial 4229 de 2002, ampliou as atribuições e criou propostas de ações junto ao governo. Houve a inclusão dos direitos sociais, econômicos e culturais com vistas a uma práxis das políticas públicas (Gorczevski; Konrad, 2013). O PNDH II contemplava cinco eixos orientadores: Educação básica, Educação superior, Educação não formal, Educação dos profissionais dos sistemas de Justiça e Segurança Pública e Educação e Mídias.

Foram vários os avanços observados do PNDH III em relação aos anteriores, dentre eles:

[...] o PNDH III avançou ao estabelecer diretrizes e ações destinadas à proteção da terra e dos territórios tradicionais. (...) Outra inovação do processo de construção do PNDH é a tentativa de incorporação dos impactos do modelo de desenvolvimento em curso no país sobre os direitos humanos. O direito ao meio ambiente e ao desenvolvimento sustentável foi, portanto, incorporados pelo programa, não só como elementos necessários a conformação da conjuntura, mas como direitos humanos. (...) O PNDH III também incorporou diretrizes dirigidas à promoção, defesa e proteção da ação dos defensores de direitos humanos. Os instrumentos anteriores sequer mencionavam a temática dos defensores, cujo papel é essencial à construção de uma cultura de direitos no país e à consolidação da democracia (Ciconello, Pivato \& Frigo, 2009, p. 4-5).

A revisão dos pontos a serem refletidos na proposição deste tipo de política pública amplia-se continuamente, pois questões fundamentais como a proteção das terras indígenas e quilombolas, ao se referir à proteção da terra, dos territórios tradicionais, é no mínimo um reconhecimento às violações cometidas contra esses grupos sociais e preservação das raízes da cultura brasileira. Também, de questões essenciais como o meio ambiente e sustentabilidade, e as ações de defesa e proteção em defesa dos militantes de Direitos Humanos.

No que se refere à formulação de um Plano Nacional de Educação em Direitos Humanos (PNEDH), o Eixo Orientador V do PNDH III, que trada da educação e cultura em Direitos Humanos, propõe cinco diretrizes destinadas a esse fim, dentre elas, destacam-se a efetivação das diretrizes e dos princípios da política nacional de educação em Direitos Humanos para fortalecer cultura de direitos; o fortalecimento dos princípios da democracia e dos Direitos Humanos nos sistemas de educação básica, nas instituições de ensino superior e nas instituições formadoras e a Promoção da Educação em Direitos Humanos no serviço público.

A importância desse documento se dá devido à apresentação das diretrizes pensadas para a implantação da Educação em Direitos Humanos no ensino brasileiro em seus vários níveis por meio dos objetivos estratégicos que norteiam as ações que irão constituir o PNEDH, ou seja, a parte prática da implantação da Educação Em e para os Diretos Humanos em tal ensino.

A diretriz 18 trata da efetivação das diretrizes e dos princípios da política nacional de educação em Direitos Humanos para fortalecer cultura de direitos. Para isto, traçou como objetivos a implementação do PNEDH na extensão de todo o território nacional, assim como a produção de materiais pedagógicos para a Educação em Direitos Humanos.

Tais diretrizes são de significativa importância na formação de uma cultura em Direitos Humanos e na disseminação do conhecimento das políticas públicas, contudo, também se apresentam grandes desafios, pois levar tais políticas públicas ao conhecimento dos atores educacionais e sociais implica no enfrentamento de fatores dificultadores tais como falta de vontade política, a grande extensão do país, uma política verticalizada de cima para baixo, contextos sociais diversos, dentre outros.

No que se refere a diretriz 19, a temática em questão é o fortalecimento dos princípios da democracia e dos Direitos Humanos nos sistemas de educação básica, nas instituições de Ensino Superior e nas instituições formadoras. Os objetivos propõem a inclusão das temáticas da Educação em e para os Direitos Humanos nas escolas de educação básica e nas instituições formadoras. Também objetiva a inclusão da temática nos cursos das IES. Ademais, trata do incentivo à transdisciplinaridade e transversalidade nas atividades acadêmicas em Direitos Humanos. 
A diretriz 21 trata da promoção da Educação em Direitos Humanos no serviço público e seus objetivos referem-se à forma e capacitação continuada dos servidores públicos. Neste caso, voltadas para a formação dos agentes de Educação.

Assim, as diretrizes e objetivos apresentados no eixo orientador que trata da Educação e cultura em Direitos Humanos estão norteando e compondo o PNEDH. Este documento aponta para um compromisso entre o Estado, por meio de seus membros, em especial o Poder Executivo em suas esferas, e os organismos internacionais, instituições de Ensino Superior e a sociedade civil organizada, na implementação de políticas públicas por uma cultura educacional em e para os Direitos Humanos.

No que se refere à concretização das diretrizes acima descritas, podem-se perceber que as políticas públicas, tendo por base sua normatização, têm se empenhado na realização dos compromissos firmados. No entanto, ainda que não seja perceptível constatar essas políticas na prática, primeiro porque são recentes e leva-se tempo significativo para que elas se efetivem, segundo porque muito do que se é proposto, já existe na legislação brasileira devido ao que está previsto nas políticas nacionais.É por isso que na maior parte do PNEDH afirma-se a questão do fortalecimento daquilo que já se prevê na própria Constituição e, também, em outros documentos como a Lei de Diretrizes e Bases da Educação brasileira. Observam-se que muitas das leis brasileiras, que já estão em vigor, não são aplicadas, ferindo princípios básicos de Direitos Humanos.

\section{Ações Programáticas para a Educação em Direitos Humanos nas IES}

As ações programáticas constituem-se em vinte e uma previsões constantes no PNEDH para a educação em e para os Direitos Humanos. Nelas estão contidas as ações e proposições para que também as Instituições de Ensino Superior (IES) possam promover a informação e formação dos estudantes.

Promover a informação e a formação em Direitos Humanos é criar uma cultura que converge com a proposta fim da Educação, a promoção da dignidade humana, o desenvolvimento em seus diversos aspectos e a promoção da cidadania emancipadora. Isso implica em repensar as estruturas educacionais: o currículo, as práticas das instituições e as políticas para a Educação. É nesse contexto que o PNEDH propõe uma reflexão por meio de ações que possam suscitar a discussão nos espaços de educação e resignificar o currículo e as práticas educacionais.

Nessa conjuntura, o Ensino Superior tem relevante papel, pois além de formar os sujeitos profissionalmente, possibilitando a sua autonomia econômica e sua inserção social, as IES também promovem uma Educação multicultural. Essa formação, alinhada aos pressupostos dos Direitos Humanos constrói práticas educativas e éticas comprometidas com a difusão, defesa, e promoção dos Direitos Humanos quer em âmbito individual ou coletivo.

As ações do PNEDH para o Ensino Superior propõem inicialmente a inclusão e a promoção da temática dos Direitos Humanos no currículo, assim como a divulgação e o conhecimento do tema por parte da sociedade. Em um segundo momento propõe a pesquisa como uma forma de maturação e ampliação da reflexão acerca da temática e por fim apresenta sugestões de fomento dos Direitos Humanos nos espaços de educação.

O fomento à disseminação da Educação em Direitos Humanos é referenciado nas ações por meio da criação de canais de propagação como fóruns, núcleos, comissões, centros de pesquisa, extensão, criação de setores de livros e periódicos, assim como a criação de prêmios, congressos, seminários em Direitos Humanos.

\section{Considerações Finais}

Tradicionalmente, os Direitos Humanos são os assim chamados direitos naturais, que se constituem como critérios de morais de especial relevância para a convivência humana. É na conjuntura das intensas e rápidas transformações sociais que tem ganhado espaço a luta de vários grupos sociais por uma educação que atenda e garanta os Direitos Humanos. 
Sabemos que esses direitos não são concessões do Estado para o cidadão, mas, sobretudo, fruto de intensas lutas. Na prática, eles não são dados, mas conquistados. No processo de conquista pelos Direitos Humanos, as leis constituem uma referência muito importante, pois uma verdadeira democracia somente se desenvolve onde os Direitos Humanos sejam reconhecidos por uma Constituição (Bobbio, 1987).

E no que diz respeito aos Direitos Humanos, a educação brasileira para o Ensino Superior é normatizada por legislações gerais e específicas tais como a Constituição Federal, o Plano Nacional de Educação, a Lei de Diretrizes e Bases da Educação, as Diretrizes Curriculares Nacionais, os Referenciais Curriculares Nacionais dentre tantos outros documentos legais. As instituições educacionais devem cumprir as exigências mínimas para a elaboração dos cursos de licenciaturas e bacharelado, e neste cumprimento encontram-se respaldadas a ofertar o Ensino Superior como uma das garantias fundamentais ao cidadão que é o direito de estudar.

Por meio das políticas públicas educacionais de financiamento estudantil, o Estado tem promovido a oferta dessa etapa de ensino para a população com o intuito de se manter como um país em pleno desenvolvimento econômico, necessitando para isto da mão de obra qualificada de seus profissionais. Nesse contexto, o Brasil busca um alinhamento com o cenário mundial seguindo uma tendência do que está acontecendo em outros países já desenvolvidos e os em pleno desenvolvimento.

No que concerne à formação em e para os Direitos Humanos, o Brasil cumpre uma agenda internacional na proposição de políticas públicas para esse fim. Esse cenário é propício à discussão sobre essas políticas, refletidas e positivadas como o PNDH e o PNEDH. Contudo, a adesão por parte das instituições e as discussões isoladas no sentido de se realizar um alinhamento que leve os estabelecimentos educacionais a se adequarem e incluírem tal temática nos seus nichos educacionais são muito lentas.

A falta de conhecimento das políticas públicas para a Educação para os Direitos Humanos por parte dos agentes educacionais também é um fator que dificulta a efetivação dos currículos. No Brasil, por exemplo, o PNDH foi publicado em 2009 tendo sido aprovado pelo Decreto nº 7.073/2009 e sua vigência a partir desse ano. Mesmo havendo as políticas públicas educacionais, o conhecimento e aplicação destas não são tão rápidos quanto a sua necessidade.

A disseminação das delas não acontece de imediato devido a fatores diversos. Entretanto, isso não justifica a falta de observância por parte dos agentes educacionais às leis. As Universidades possuem uma autonomia outorgada pela CF/88 no âmbito didático, científico, administrativo, financeiro e patrimonial em atenção ao princípio do ensino, pesquisa e extensão. Desta forma, a responsabilidade torna-se partilhada no que se refere ao compromisso com as políticas públicas emergentes.

As políticas públicas para a Educação em Direitos Humanos, tomando como parâmetro as preocupações das nações acerca desta temática, são relativamente contemporâneas. Esse fato gera várias limitações neste tipo de análise, pois se incorre no risco de generalizações.

A percepção do outro como igual em direitos e deveres é uma compreensão inerente a todos os sujeitos, ou deveria ser, partindo do pressuposto de que possuem constituições semelhantes tanto físicas quanto biológicas.

Dessa forma, os direitos humanos buscam uma convergência do respeito e diálogo no que se refere às diferenças e aos interesses que os grupos sociais buscam defender. Essas relações dialógicas favorecem um crescimento coletivo em meio à diversidade, proporcionando um ambiente favorável à vida. Compreender os Direitos Humanos e aplicá-los na vida é uma das formas de emancipação social. No Brasil, em especial, um dos grandes problemas está relacionado à execução das leis e efetivação das garantias sociais aos cidadãos.

Ao se visualizar os objetivos dos mais de 70 anos da Declaração Universal de Direitos Humanos, confirmou-se as percepções de que uma das finalidades da Educação converge com o objetivo dos Direitos Humanos de uma formação voltada para a humanização dos sujeitos. Na Educação, essa formação torna-se possível por um conjunto de ações que tem início no 
currículo que constituiu uma importante via de possibilidade enquanto um instrumento político que potencializa as ações educacionais permitindo que a Educação em para os Direitos Humanos seja possível.

Construir uma cultura em Direitos Humanos implica na postura prática da coletividade em torno do daquilo que se deseja alcançar. Trata-se de comportamentos e ações promotoras dos Direitos Humanos.

\section{Referências}

Alves, J. A. L. (2005). Os direitos humanos na pós-modernidade. Perspectiva.

Bardin, L. (2011). Análise de conteúdo. Edições 70.

Bordieu, P. (1983). A juventude é apenas uma palavra. In: Bordieu, Pierre. Questões de Sociologia. Marco Zero. 112-121.

Bobbio, N. (2004). A era dos direitos. Elsevier.

Bobbio, N., \& Matteucci, N. P. G. (1998). Dicionário de Política. Editora Universidade de Brasília

Bobbio, N. (1987). Estado, governo, sociedade: para uma teoria geral da política. (2a ed.), Paz \& Terra.

Brasil. Constituição (1988). Constituição da República Federativa do Brasil. Brasília, DF: Senado Federal: Centro Gráfico, 1988.

Brasil. Plano Nacional de Educação em Direitos Humanos: 2007. Comitê Nacional de Educação em Direitos Humanos. Brasília: Secretaria Especial dos Direitos Humanos, Ministério da Educação, Ministério da Justiça, UNESCO, 2007. http://portal.mj.gov.br/sedh/edh/pnedhpor.pdf

Brasil. Senado Federal. Direitos Humanos: atos internacionais e normas correlatas. Coordenação de edições técnicas. (4a ed.), Brasília, 2013.

Chauí, M. Santos, B. de S. (2013). Direitos Humanos, democracia e desenvolvimento. Cortez.

Comparato, F. K. (2013). A afirmação histórica dos direitos humanos. (8a ed.), Saraiva.

Conceição, M. M. (2012). Os empresários do lixo; um paradoxo da modernidade. (2a ed.), editora Átomo Aline.

Creswell, J. W. (2010). Projeto de Pesquisa: método qualitativo, quantitativo e misto. Artmed.

Dallari, D. de A. (2002). Direitos Humanos e Cidadania. Editora Moderna.

Declaração dos Direitos do Homem e do Cidadão de 1789. http://pfdc.pgr.mpf.mp.br/atuacao-e-conteudos-de-apoio/legislacao/direitosuhmanos/declar_dir_homem_cidadao.pdf.

Dewey, J. (1979). Educação e Democracia.

Dias, A. A. (2010). Da educação como direito humano aos direitos humanos como princípio educativo. In: Educação em Direitos Humanos: Fundamentos teórico-metodológicos. Silveira, Rosa Maria Godoy, et al. João Pessoa: Editora Universitária/UFPB.

Estêvão, C. V. Democracia, Direitos Humanos e Educação: Para uma perspectiva crítica de educação para os direitos humanos. Rev. Lusófona de Educação. (17). http://www.scielo.gpeari.mctes.pt/scielo.php?script=sciarttext\&pid=S1645-72502011000100002\&lng=pt\&nrm=iso

Estêvão, C. V. Futuros educadores: a nebulosa conexão do mercado e da ágora no nível dos direitos humanos e da justiça: encruzilhadas do Ensino Superior. In: Caliman, Geraldo (Org.). Direitos humanos na pedagogia do amanhã. Brasília: UNESCO, 2014.

Feitosa, M. L. P. de A. M. O Currículo de Direitos Humanos no Ensino Superior e na Pós-Graduação. Revista Eletrônica Espaço do currículo, João Pessoa-PB, ano $1, \mathrm{n}^{\circ} .2 . \mathrm{http}: / /$ www.aepppc.org.br/revista/.

Franco, M. L. (2008) Análise de conteúdo. Liber Livro.

Freire, P. (1997) Pedagogia da Autonomia. Paz e Terra.

Gatti, B. (2012). Grupo focal na pesquisa em ciências sociais e humanas. Liber Livro

Gil, A. C. (2010). Métodos e técnicas de pesquisa social. Atlas,

Gorczevski, C. (2009). Direitos humanos, educação e cidadania: conhecer, educar, praticar. Edunisc

Gorczevski, C., \& Martín, N. B. (2015). Educar para os Direitos Humanos: considerações, obstáculos, propostas. Editora Atlas,

Konrad, L. R.; \& Gorczevski, C. (2013). A Educação e o Plano Nacional de Educação em Direitos Humanos: Efetivando os Direitos Fundamentais no Brasil. Revista do Direito UNISC, Santa Cruz do Sul, RS, (39).

Novaes, R. A velocidade da informação e os desafios para a juventude. In: Cândido, A. G. (Org.). Juventude: Possibilidades e limites. Brasília: UNESCO: UCB, 2011.

Nóvoa, A. Formação de professores e profissão docente. Dom Quixote (1992). 
Research, Society and Development, v. 10, n. 1, e48010112032, 2021

(CC BY 4.0) | ISSN 2525-3409 | DOI: http://dx.doi.org/10.33448/rsd-v10i1.12032

Organização Das Nações Unidas (ONU). Declaração Universal dos Direitos Humanos. Paris, 10 de dezembro de 1948. <http://www.onu.org.br/img/2014/09/DUDH.pdf>.

Piovesan, F. (2010). Direitos humanos e direito constitucional internacional. (11a ed.) Saraiva.

Ruiz, C. M. M. B. (2010). Os direitos humanos como direitos do outro. In: Ferreira, L. de F. G., Zenaide, M. de N. T.; \& Pequeno, M. (Orgs.). Direitos humanos na educação superior. Subsídios para a educação em direitos humanos na filosofia. Editora Universitária UFPB. 